\title{
Seismic remote monitoring of stress field
}

\author{
Eiichi Fukuyama, Atsuki Kubo, Hiroyuki Kawai, and Ken'ichi Nonomura \\ National Research Institute for Earth Science and Disaster Prevention, 3-1 Tennodai, Tsukuba, Ibaraki 305-0006, Japan
}

(Received November 21, 2000; Revised August 10, 2001; Accepted August 21, 2001)

\begin{abstract}
We demonstrate that a real-time based moment tensor analysis using broadband seismic waveforms provides us with the information about the spatio-temporal change of stress field. Such a capability is crucial when monitoring the volcanic activity during the eruption if it causes seismic swarm. We estimated the moment tensors of earthquakes occurring during the swarm activity before the eruption of Usu volcano in March 2000 as well as those during the swarm activity of Miyakejima volcano starting in June 2000. In both cases, we detected the stress change due to the movement of magma reservoir.
\end{abstract}

\section{Introduction}

Recently, moment tensor analysis is conducted routinely. In the global scale, Harvard University (HRV) (e.g. Dziewonski et al., 1981), US Geological Survey (USGS) (Sipkin, 1982), and ERI, University of Tokyo (Kawakatsu, 1995) have been estimating the moment tensors based on the NEIC earthquake locations. In the regional scale, UC Berkeley (Pasyanos et al., 1996) determines moment tensors in northern California using sparse broadband seismic network.

In Japan, before the nation-wide broadband seismic network started to work in 1996, focal mechanisms estimated by the polarities of $P$-wave fast motions were only available for local earthquakes. However, after the development of the broadband seismic network (FREESIA) (Fukuyama et al., 1996), moment tensor analysis of earthquakes with magnitudes greater than 3.5 has been conducted routinely by the National Research Institute for Earth Science and Disaster Prevention (NIED) (Fukuyama et al., 1998, 1999, 2000a, 2000b, 2001a, 2001b).

This system enables us to determine robust moment tensors immediately after the event using information (origin time in minutes and hypocenter location in 0.1 degrees) of an earthquake provided by Japan Meteorological Agency (JMA). The solution is stable because this analysis tries to fit long period waveforms (20-100 s) which are relatively insensitive to the crustal structure as well as to the location error of epicenters.

Thus this system is suitable for the analysis of volcanic swarm that produces plenty of earthquakes within a short period and the spatio-temporal variation of stress field brings an important information about the magmatic activity. Here we will show a couple of examples of the analysis of volcanic swarm activity that provided us with the stress state during the eruption of the volcano.

Copy right (C) The Society of Geomagnetism and Earth, Planetary and Space Sciences (SGEPSS); The Seismological Society of Japan; The Volcanological Society of Japan; The Geodetic Society of Japan; The Japanese Society for Planetary Sciences.

\section{Stress Field around Japan Island}

Concerning the stress field around the Japan islands, there exists the stress field map by compiling focal mechanism solutions of $P$-wave first motions determined by JMA (Ichikawa, 1971) and by the Kanto-Tokai micro-seismic network (Tsukahara and Ikeda, 1991). However, due to the development of the FREESIA broadband seismic network, moment tensor solutions are routinely determined and stress field could be estimated by compiling the moment tensor solutions around the Japan islands.

For earthquakes after 1976, HRV has determined the centroid moment tensors (CMT) of large earthquakes $\left(M_{w}>\right.$ 5 ). In order to confirm the reliability of the NIED moment tensor (MT) solutions, we compared the NIED MT catalogue with the HRV CMT.

In Fig. 1, $P$-axis distribution of shallow earthquakes are shown for both catalogues. The HRV catalogue consists of earthquakes for about 24 years, while the NIED catalogue is for about 4 years long. Looking at the region around the Japan Island, both catalogues are very similar. In the inland region, the NIED catalogue provides more detailed variation of stress field. It should be noted that the 4-year NIED catalogue is almost compatible to the 24 years HRV catalogue. And we will be able to obtain more precise stress field in the near future by accumulating such NIED MT solutions. More importantly, we might be able to catch the temporal change of stress field around Japan.

Figure 2 shows the dominant magnitude range in each catalogue. The NIED MT catalogue covers earthquakes whose magnitudes are greater than 3.8, while the HRV CMT catalogue covers for those greater than 5.3. Since no $M>7$ earthquake occurred since 1997 within the FREESIA network around Japan island, the NIED catalogue does not include such a large earthquake.

In Fig. 3, the differences of the direction of stress axes $(P-, B-$, and $T-)$ between NIED MT and HRV CMT catalogues are shown. The angles between two stress directions are measured in 3-D space. We used the common 226 earthquakes from both catalogues. In this figure we can see that the misfit in both catalogues are about $15^{\circ}$. This differ- 


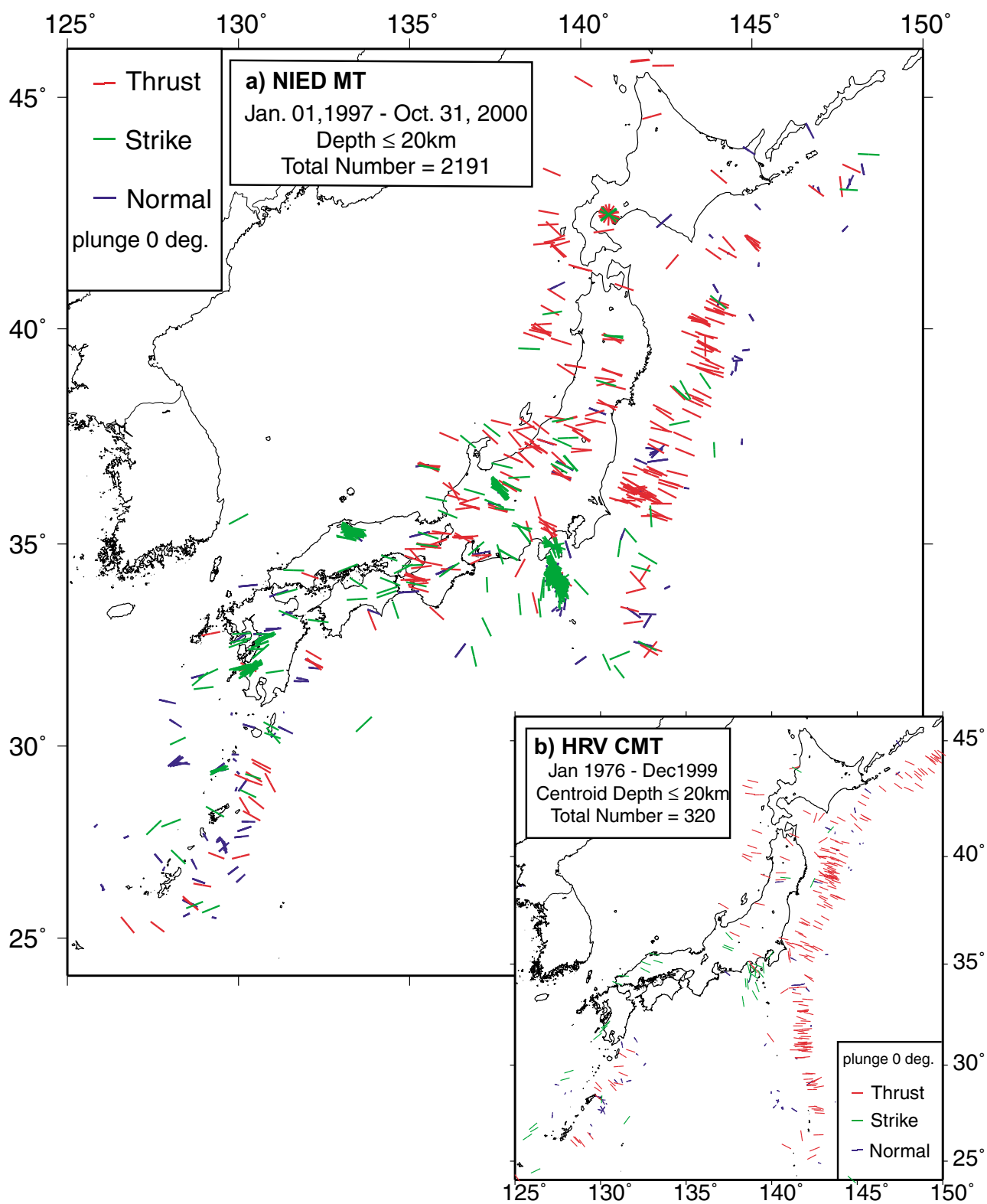

Fig. 1. (a) $P$-axis distribution of the NIED MT solutions determined by the National Research Institute for Earth Science and Disaster Prevention using FREESIA broadband seismic network. (b) $P$-axis distribution of the HRV solutions determined by the Harvard University using worldwide broadband seismic network. All earthquakes whose depth is shallower than $20 \mathrm{~km}$ are plotted. "Thrust", "Strike", and "Normal" indicate thrust fault, strike slip fault, and normal fault, respectively. The focal mechanism is classified by the directions of $B$ - and $T$-axes.

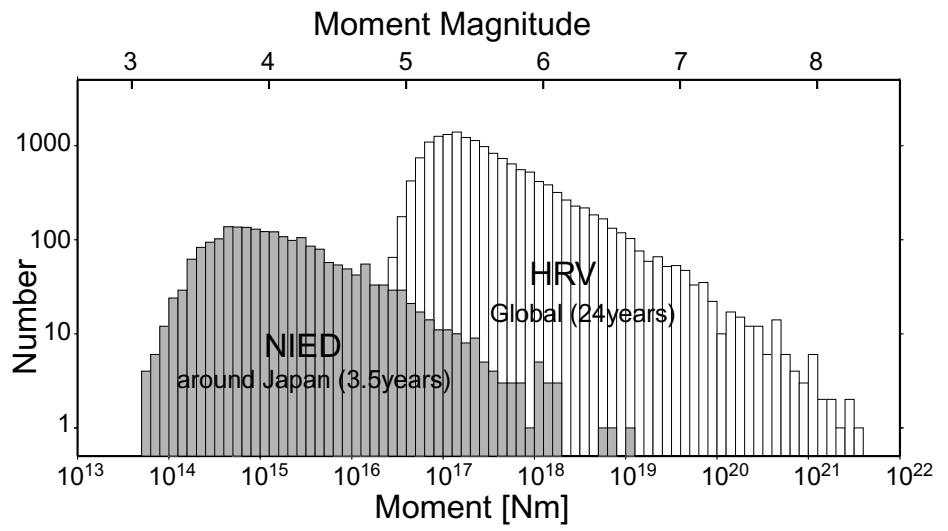

Fig. 2. Total number of earthquakes in both NIED and HRV catalogues is plotted as a function of seismic moment. The period range of the NIED catalogue is from January 1997 to June 2000 and that of the HRV is from January 1976 to May 1999. 

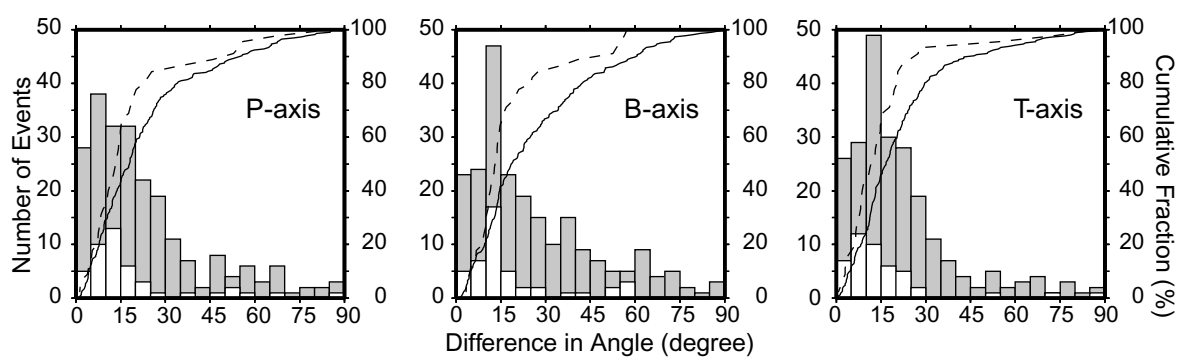

Fig. 3. Comparison of $P-, B$-, and $T$ - axes directions between NIED MT and HRV CMT catalogues. Angles are measured in 3-D space. Both histograms and cumulative fraction curves are plotted. White bars and dotted lines are for big earthquakes whose scalar moments are greater than $3.16 \times 10^{17} \mathrm{Nm}$.

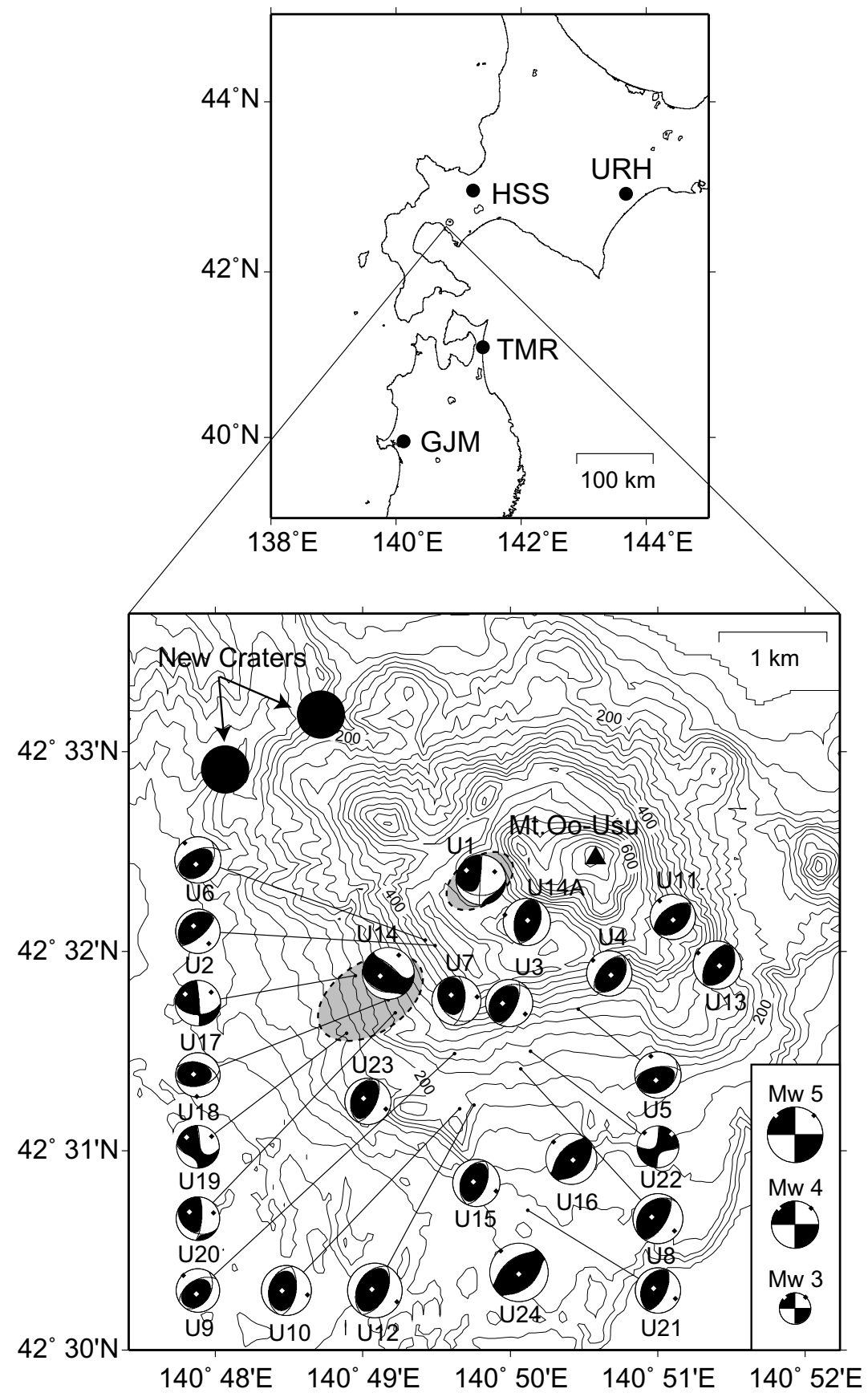

Fig. 4. (Upper) Station distribution used in this analysis. (Lower) Moment tensors before the eruption of Usu volcano. Gray area surrounded by dotted line indicates the region where the compressional axis are rotated in 90 degrees from the background global stress field. The location of new craters created by this volcanic activity is also shown. 


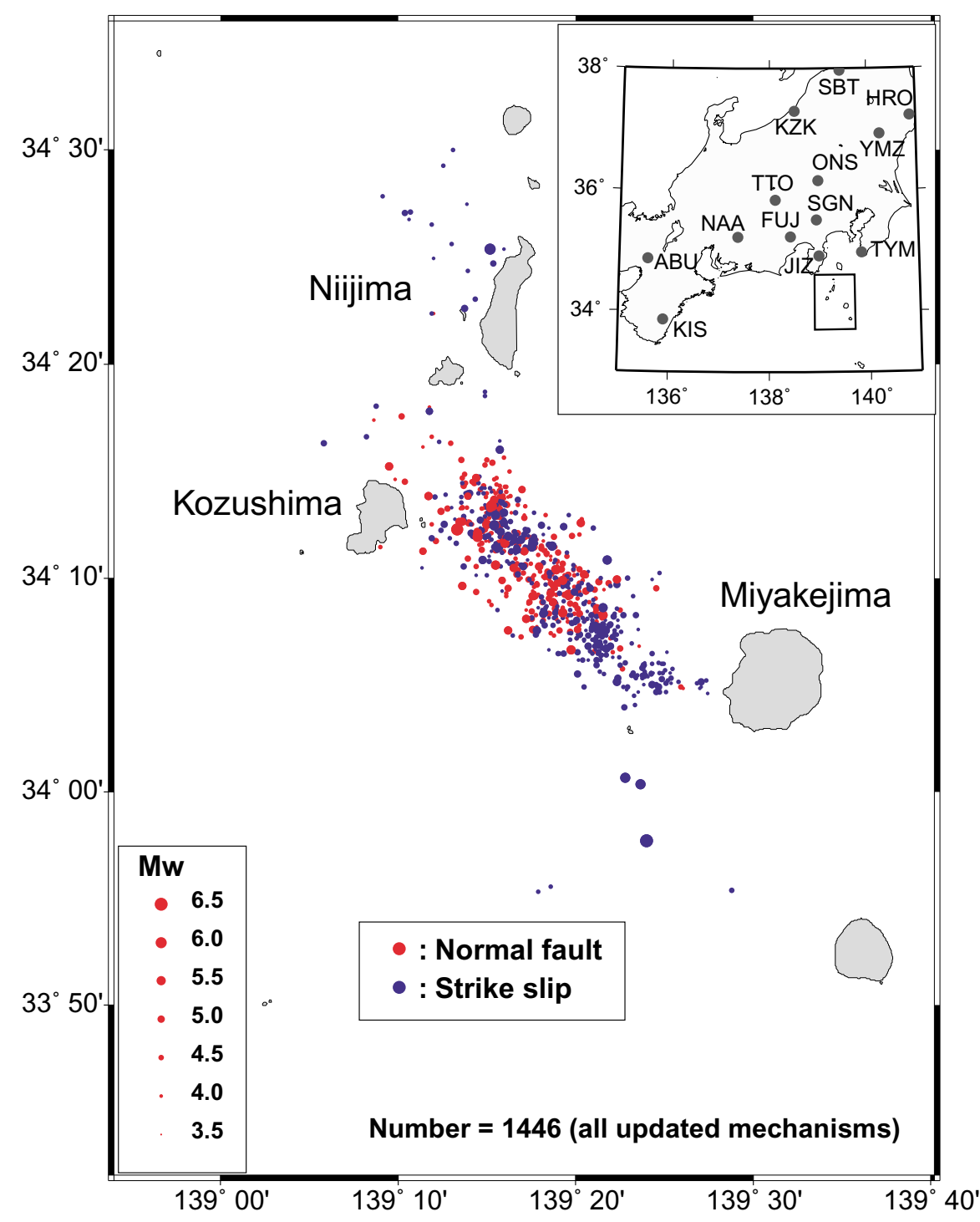

Fig. 5. The epicenters of earthquake swarm occurring from June 27, 2000 to September 19, 2000. Strike slip (blue) and normal fault (red) earthquakes are observed. The size of symbol is proportional to its magnitude. Station distribution is also shown in the upper right panel.

ence is almost the same as that obtained by the comparison between HRV, USGS and ERI catalogues (Helffrich, 1997; Frohlich and Davis, 1999). It should be emphasized that the input data are generally common for most global catalogues, while, in the present comparison, the input waveform data are completely independent.

It should be noted that the directions of stress axes obtained by moment tensor solutions are not always the same as those of the stress field because moment tensor solution is a point source approximation of slip at the source instead of the stress glut. However, compiled distribution of stress axes might reflect the dominant stress direction. Also, spatiotemporal change of the axis direction could be an index of the change of stress field in space and time.

\section{Stress Field Change due to the 2000 Eruption of the Usu Volcano}

Usu volcano became active with seismic swarm on March 27, 2000 after about 20 years of quiescence. On March 31, four days later, it started to erupt at the west/northwest flank of the volcano. Until the eruption we observed and analyzed about 50 earthquakes whose magnitudes are greater than 3.5 (maximum is $M_{w} 4.9$ ). Among these earthquakes, we plotted 25 earthquakes in Fig. 4 (Fukuyama and Kubo, 2000) whose hypocentral informations are provided by JMA. Most earthquakes had thrust fault mechanism. The depths are about $5 \mathrm{~km}$. However, since in the moment tensor analysis the shallowest depth is assumed to be $5 \mathrm{~km}$, the real depth might be a bit shallow. During the most seismically active period, large crustal deformation was observed that reached several meters. After the eruption, the deformation rate became very small (M. Kasahara, personal communication). Thus, in the seismically active period, stress change in the crust might be very high, that caused many earthquakes.

It should be noted that south of the new craters (the region surrounded by the dotted line in Fig. 4) the fault mechanisms are different from the others. Most earthquakes have northwest-southeast compressional axis, which is consistent with the large scale tectonic stress field in this region (Stauder and Mualchin, 1976; Harada, 1981). On the other 


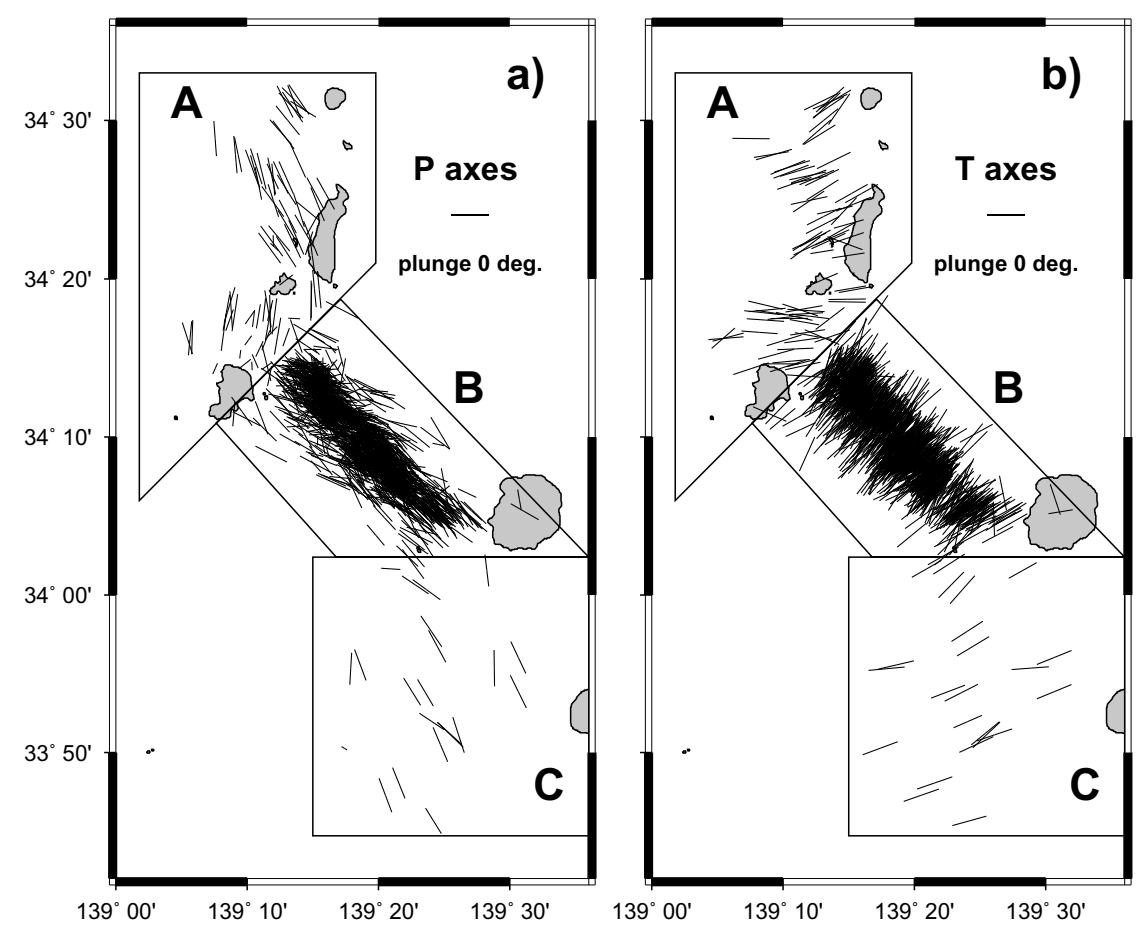

Fig. 6. (a) compressional axis and (b) dilatational axis distribution during the swarm activity from June 27 to September 13, 2000. Three regions (A, B, and $\mathrm{C}$ ) are identified according to the direction of stress axes.

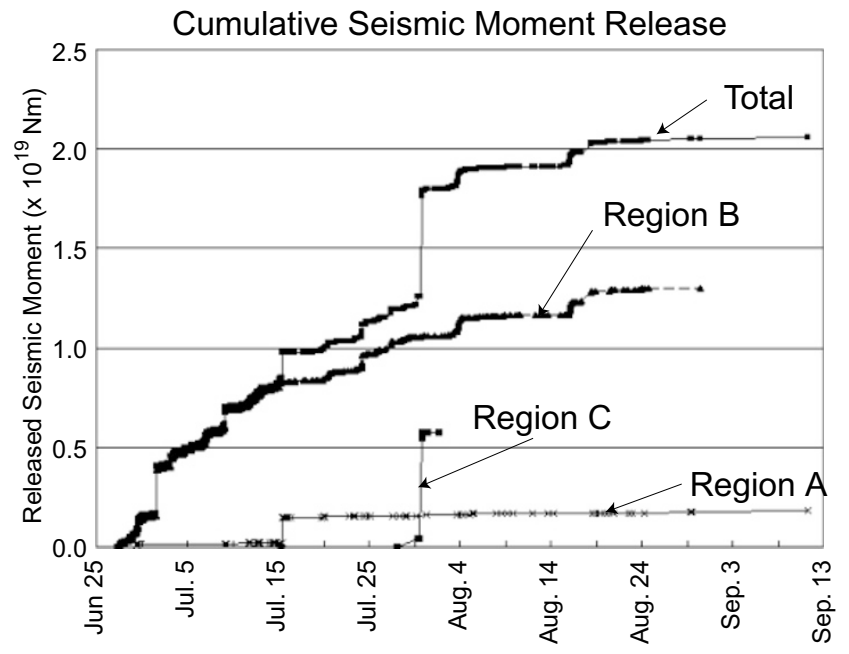

Fig. 7. Cumulative moment release curve determined by the moment tensor analysis. "cross" symbol corresponds to each earthquake. The cumulative curve for each region (A, B, and $\mathrm{C}$ in Fig. 6) is also shown.

hand, the earthquakes occurring south of the new craters have northeast-southwest compressional axis, which is rotated in 90 degrees. This abnormal stress field might be caused by the volcanic activity, especially, the movement of the magma of Usu volcano.

4. Stress Field during the Seismic Swarm Activity near the Kozushima-Miyakejima Region Caused by the 2000 Eruption of Miyakejima Volcano

On June 27, 2000, the swarm activity started under Miyakejima volcano and extended toward the Kozushima/ Niijima islands. This swarm produced a lot of seismicity that included several magnitude 6 events (7/1 07:02 UT $M_{w}$ 6.2, 7/8 18:57 UT $M_{w}$ 5.9, 7/15 01:30 UT $M_{w} 6.0,7 / 23$ 21:52 UT $M_{w} 5.6,7 / 30$ 12:25 UT $M_{w} 6.4,8 / 18$ 01:52 UT $M_{w}$ 5.7). This activity is considered to be the biggest swarm in the 20th century in Japan. Moreover the volcanic activity also became active simultaneously with seismic swarm (Ukawa et al., 2000). In June 27, small submarine eruption was observed near the Miyakejima island. In July 7, the volcanic eruption started at the summit of the Miyakejima volcano and it continued to be active for a couple of months. At 09:41 UT on July 8, a long period earthquake occurred beneath the Miyakejima volcano. This earthquake triggered the periodic occurrence of long period (50 seconds) earth- 
quakes which were correlated with the inflation/deflation of the Miyakejima volcano (Ukawa et al., 2000).

During this period, we routinely estimated the moment tensors without significant delay. In two months, we have determined about 1500 earthquakes, which correspond to those for three whole years in the normal seismic activity around Japan.

As shown in Fig. 5, all earthquakes are either strike slip faults or normal faults. The normal fault earthquakes were located in the shallow part (around $5 \mathrm{~km}$ ) and strike slip earthquakes were located at greater depths $(5 \mathrm{~km}-17 \mathrm{~km})$. The normal fault earthquakes occurred only in the region B denoted in Fig. 6, while strike slip faults occurred in all regions.

Figure 6 shows the compressional and dilatational axes. In regions $\mathrm{A}$ and $\mathrm{C}$, compressional axes directed to northsouth, which is consistent with the past activity in this region and coincided with the global stress field. However, in region $\mathrm{B}$, stress field is apparently different from the global stress field and has northwest-southeast compressional axes.

The cumulative moment release curve is shown in Fig. 7. In region $\mathrm{B}$, it increased logarithmically. However, in region $A$ and $C$, it increased step-wisely. This suggests that in region $\mathrm{B}$, the volcanic phenomenon such as the movement of magma was continuously undergoing. In regions $\mathrm{A}$ and $\mathrm{C}$, the crust tried to release the stress accumulated by the volcanic activity in region B. By examining the detailed stress field, we will be able to understand what is going in region B. It should be noted that this logarithmic curve is consistent with that of the distance change between Kozushima and Niijima islands observed by the GPS measurements (Kaidzu et al., 2000). This implicitly suggests that this moment release curve monitors the dike intrusion in region $\mathrm{B}$.

Finally, it should be emphasized that since we did not use the waveform data in the Miyakejima island but observed in the main Japan island, we could continuously monitor the stress field in spite of the electrical power outages and communication line failures in the Miyakejima island during the volcanically active period.

\section{Conclusion}

We have successfully estimated the stress field by the moment tensor analysis using broadband seismic waveforms. From about 4 years of moment tensor catalogue, stress field around the Japan islands is obtained, which is comparable to the 24 years HRV CMT catalogue and is much better than the traditional $P$-wave fast motion focal mechanism catalogue by the local microseismic network. Further data accumulation will help more detail of analysis such as detecting temporal change of the stress field.

The latter point was demonstrated by analyzing the moment tensors of earthquakes during the volcanic swarm activity. We could detect the stress field anomaly as well its temporal variation. This kind of information is crucial to understand the movement of the magma.

Acknowledgments. Hypocentral locations are provided by the Unified hypocenter catalog maintained by the Japan Meteorological Agency. Comments by Professors Toshiro Tanimoto, Raul Madariaga, and Takaya Iwasaki were helpful to improve the manuscript.

\section{References}

Dziewonski, A. M., T.-A. Chou, and J. H. Woodhouse, Determination of earthquake source parameters from waveform data for studies of global and regional seismicity, J. Geophys. Res., 86, 2825-2852, 1981.

Frohlich, C. and S. D. Davis, How well constrained are well-constrained T, $\mathrm{B}$, and $\mathrm{P}$ axes in moment tensor catalog?, J. Geophys. Res., 104, 49014910, 1999

Fukuyama, E. and A. Kubo, Moment tensor solutions for the earthquakes ( $M \sim 4$ ) before the eruption of Usu volcano, Report of the Coordinating Committee for Earthquake Prediction, 64, 24-27, 2000 (in Japanese).

Fukuyama, E., M. Ishida, S. Hori, S. Sekiguchi, and S. Watada, Broadband seismic observation conducted under the FREESIA project, Report of the National Research Institute for Earth Science and Disaster Prevention, 57, 23-31, 1996 (in Japanese with English abstract).

Fukuyama, E., M. Ishida, D. S. Dreger, H. Kawai, Automated seismic moment tensor determination using on-line broadband seismic waveforms, Zisin (J. Seismol. Soc. Jpn.), Ser. 2, 51, 149-156, 1998 (in Japanese with English abstract)

Fukuyama, E., M. Ishida, S. Horiuchi, H. Inoue, S. Hori, S. Sekiguchi, H. Kawai, and H. Murakami, NIED seismic moment tensor catalogue January-December 1998, Technical Note of the National Research Institute for Earth Science and Disaster Prevention, 193, 1-35, 1999.

Fukuyama, E., M. Ishida, S. Horiuchi, H. Inoue, S. Hori, S. Sekiguchi, H. Kawai, H. Murakami, S. Yamamoto, K. Nonomura, and A. Goto, NIED seismic moment tensor catalogue January-December 1999, Technical Note of the National Research Institute for Earth Science and Disaster Prevention, 199, 1-56, 2000a.

Fukuyama, E., M. Ishida, S. Horiuchi, H. Inoue, S. Hori, S. Sekiguchi, A. Kubo, H. Kawai, H. Murakami, and K. Nonomura, NIED seismic moment tensor catalogue January-December 1997, Technical Note of the National Research Institute for Earth Science and Disaster Prevention, 205, 1-35, 2000b.

Fukuyama, E., M. Ishida, S. Horiuchi, H. Inoue, S. Hori. S. Sekiguchi, A. Kubo, H. Kawai, H. Murakami, S. Yamamoto, and K. Nonomura, NIED seismic moment tensor catalogue January-December, 2000, Technical Note Nat'l Res. Inst. Earth Sci. Disas. Prev., 217, 1-131 2001a.

Fukuyama, E., M. Ishida, S. Horiuchi, H. Inoue, A. Kubo, H. Kawai, H. Murakami, and K. Nonomura, NIED seismic moment tensor catalogue January-December, 1998 (Revised), Technical Note Nat'l Res. Inst. Earth Sci. Disas. Prev., 218, 1-51, 2001b.

Harada, T., Stress field in Usu volcano deduced from focal mechanism solutions, Kazan (J. Volcano. Soc. Jpn.), Ser. 2, 26, 93-110, 1981 (in Japanese with English abstract).

Helffrich, G. R., How good are routinely determined focal mechanisms? Empirical statistics based on a comparison of Harvard, USGS and ERI moment tensors, Geophys. J. Int., 131, 741-750, 1997.

Ichikawa, M., Reanalyses of mechanism of earthquakes which occurred in and near Japan and statistical studies on the nodal plane solutions obtained 1926-1968, Geophys. Mag., 35, 207-274, 1971.

Kaidzu, M., T. Nishimura, M. Murakami, S. Ozawa, T. Sagiya, H. Yarai, and T. Imakiire, Crustal deformation associated with crustal activities in the northern Izu-islands area during the summer, 2000, Earth Planets Space, 52, ix-xviii, 2000.

Kawakatsu, H., Automated near-realtime CMT inversion, Geophys. Res. Lett., 22, 2569-2572, 1995.

Pasyanos, M. E., D. S. Dreger, B. Romanowicz, Toward real-time estimation of regional moment tensors, Bull. Seismol. Soc. Am., 86, 1255-1269, 1996.

Sipkin, S. A., Estimation of earthquake source parameters by the inversion of waveform data : synthetic waveforms, Phys. Earth Planet. Inter., 30 242-259, 1982.

Stauder, W. and L. Mualchin, Fault motion in the large earthquakes of the Kurile-Kamchatka Arc and of the Kurile-Hokkaido Corner, J. Geophys Res., 81, 297-308, 1976.

Tsukahara, H. and R. Ikeda, Crustal stress orientation pattern in the central part of Honshu, Japan-stress provinces and their origins-, J. Geol. Soc. Jpn., 97, 461-474, 1991 (in Japanese with English abstract).

Ukawa, M., E. Fujita, E. Yamamoto, Y. Okada, and M. Kikuchi, The 2000 Miyakejima eruption: Crustal deformation and earthquakes observed by the NIED Miyakejima observation network, Earth Planets Space, 52, xix-xxvi, 2000

E. Fukuyama (e-mail: fuku@bosai.go.jp), A. Kubo, H. Kawai, and K. Nonomura 